\title{
Transmidiação: uma tática enquanto formação de professores
}

\author{
Transmedia: a tactic while training teachers
}

\author{
Valtemir dos Santos Rodrigues ${ }^{1 *}$, Andrea Cristina Versuti ${ }^{1}$
}

\begin{abstract}
RESUMO
Este artigo apresenta resultados de uma pesquisa de cunho qualitativo cujo propósito foi investigar os desdobramentos de uma formação docente inédita em metodologia da transmidiação nas práticas pedagógicas em sala de aula aplicada a professores da educação básica do Distrito Federal. A aproximação docente com os usos dos dispositivos tecnológicos e suas linguagens nas práticas de ensino demonstrou que tal metodologia é uma tática possível para trazer o universo do estudante para a sala de aula, implementar atividades pedagógicas diferenciadas, tornar o aluno protagonista do seu processo de aprendizagem, estimular o trabalho colaborativo e descentralizar o ensino da figura do professor. A metodologia da pesquisa foi composta por revisão bibliográfica e documental, observação não participante do curso na versão piloto e regular, acompanhamento das experimentações em sala de aula em duas turmas promovidas pelos docentes do curso, análise dos portfólios dos estudantes de uma delas, e entrevistas com quatro professores participantes da formação. Ao final, ficou confirmada a hipótese de que a metodologia da transmidiação contribuiu para uma forma de aprender mais criativa, autônoma e colaborativa.
\end{abstract}

Palavras-chave: Convergência; Transmidiação Formação Docente; Multiletramentos; Multirreferencialidade.

\section{ABSTRACT}

This article aims to present results of a qualitative research with the purpose to investigate the unfolding of an unprecedented teachers training in transmedia practices in the classroom. The methodology was applied to basic education teachers in the State of Federal District of Brazil. It was concluded that with the approach of the teachers to those technological devices and their languages in teaching practices, is a possible tactic to bring the student universe to the classroom, implement different pedagogical activities, making the students the protagonist of their own learning process, stimulating collaborative work and decentralizing the figure of the teachers. The research methodology consisted of a bibliographic and documentary review, non-participant observation of the course in the pilot and regular version, monitoring of classroom experiments in two classes promoted by the course professors, analysis of the portfolios of students in one of them, and interviews with four teachers participating in the training. In the end, the hypothesis was confirmed that the methodology of transmediation contributed to a more creative, autonomous and collaborative way of learning.

Keywords: Convergence. Transmidiation, Teacher Education, Multiliteracies, Multi-referentiality.

\footnotetext{
${ }^{1}$ Universidade de Brasília - UnB.

*E-mail: valtemir.rodrigues@gmail.com
} 


\section{INTRODUÇÃO}

Com o advento das Tecnologias Digitais da Informação e Comunicação (TDICs) a sociedade tem passado por constantes transformações, promovendo novas formas de relações sociais de consumo e de convivência. Virtualmente podemos ir ao outro lado do oceano e obter informações das mais diversas. Da poltrona de casa é possível conhecer museus e locais muito diferentes com facilidade, além de inteirar-se de acontecimentos em tempo real e, principalmente, comunicar-se.

E não são apenas as formas do entretenimento e do lazer que têm sido transformadas pelas novas tecnologias, mas potencialmente todas as esferas da sociedade. Essa presença pode ser notada no mundo do trabalho, no gerenciamento político, nas atividades militares e policiais, no consumo, na comunicação, nas relações interpessoais e também na educação. Enfim, toda nossa cultura está em processo constante de mudança com participação direta dos meios digitais.

Este é o contexto da cibercultura, definido por Lévy (1999) como um novo espaço de comunicação, de sociabilidade, de organização, acesso e transporte de informação e conhecimento e no qual as nossas relações são reais, apesar de acontecerem no mundo virtual. Neste ciberespaço fazemos tudo que fazem as pessoas quando se encontram, mas o fazemos com palavras, imagens, vídeos e nas telas das interfaces computacionais. Milhões de nós pertencem a alguma rede social digital na qual nossas identidades se misturam e interagem eletronicamente (SANTAELLA, 2013, p. 123).

Todas essas possibilidades comunicativas demonstram que estamos vivendo na era da cultura digital. De acordo com Serres (2013, p. 76), é nessa conjuntura social que encontramos a população Polegarzinha, ou seja, aqueles que nasceram no fim do século XX e que estão em contato com o mundo virtual desde o seu nascimento. Por celular, têm acesso às pessoas; por GPS, a todos os lugares; pela internet, a todo saber. Não habitam mais o mesmo espaço (SERRES, 2013, p. 19).

Nessa realidade, os nascidos e criados na era tecnológica relacionam-se com o mundo de formas diferentes das que nos relacionávamos antes. De acordo com Bauman e Leoncini (2018, p. 62), um aspecto decididamente contínuo em relação aos nossos dias é a necessidade dos jovens de experimentar particular interesse por todas as realidades que encurtam ainda mais as distâncias espaciais.

WhatsApp, Telegram, Snapchat, Messenger têm esta grande função: reduzem nossos prazos, nos fazem chegar muito mais rápido ao objeto desejado; são processos instantâneos que confirmam como nunca antes o fim das distâncias espaciais, determinando como único e sutil obstáculo a barreira temporal (BAUMAN, LEONCINI, 2018, p. 62). 
Segundo a pesquisa TIC Kids Online, realizada com estudantes entre 09 e 17 anos nas escolas brasileiras, em 2018, ano anterior a pesquisa, mostrou que: $86 \%$ dos estudantes eram usuários de internet; 83\% reportaram ter assistido vídeos, programas, filmes e séries on-line; 83\% possuíam perfis em redes sociais; $77 \%$ enviaram mensagens instantâneas e $82 \%$ escutaram música on-line. No ano anterior, a mesma pesquisa revelou que a web era utilizada por $80 \%$ dos estudantes para produzir trabalhos escolares; $65 \%$ para fazer exercícios e lições que o professor passa; $86 \%$ para realizar pesquisas escolares; $56 \%$ para jogos educativos; $26 \%$ para falar com o professor; $73 \%$ para produzir trabalhos em grupo e $72 \%$ para estudar para provas.

Neste cenário, apenas os usos do giz, da lousa e do livro didático se mostram insuficientes para o êxito do processo formativo demandando com isso outra forma de ensinar que envolva e traga o estudante para o processo de construção do conhecimento. Esses jovens estão conectados em rede, possuem acesso facilitado às informações, são produtores de conteúdos (vídeos, textos, músicas, charges, memes), jogam em ambiente on-line e tudo isso é pouco explorado no ensino público.

Frente a esse cenário desafiador e em constante mudança, um curso inédito no país foi proposto pelo Centro de Referência em Tecnologia Educacional de Taguatinga (CRTE) de Taguatinga no Distrito Federal, em 2018, e implementado no início de 2019 com a finalidade de familiarizar os docentes com essas linguagens e investigar suas potencialidades para o campo educacional. A formação continuada intitulada Uso de Ferramentas Digitais para Otimização do Processo de Aprendizagem (UFDOPA), iníciou no primeiro de 2019 com foco na criação e reelaboração de textos narrativos transmidiáticos por meios de dispositivos digitais.

A formação docente foi estruturada com base na metodologia da transmidiação conceituada por Versuti e Silva (2017), no qual nos pautamos neste estudo, como sendo a ação de transpor conteúdos de um sistema de significação para outro ampliando as oportunidades de sentidos e construção de conexões entre as linguagens. Esse exercício de transmidiação se originou das narrativas transmídia, que tem Jenkins (2009) como referência e que a define como uma história expandida, dividida em várias partes e distribuídas entre diversas mídias.

Por meio desse tipo de narrativa podemos criar um universo ficcional em torno de uma obra específica. Isso significa que a história de um livro pode se tornar uma obra de cinema, se transformar em histórias em quadrinhos (HQs), ser explorado em fanfiction, virar games, fazer parte de programas de televisão e até mesmo virarem produtos de mercado. Tal como é apresentada Jenkins (2009), a narrativa transmídia une as diferentes mídias disponíveis a fim de contar uma grande história através de um novo modelo de cocriação que utiliza o potencial único de cada mídia.

Portanto, nos propusemos identificar quais as repercussões uma formação docente em metodologia da transmidiação podem promover nas práticas pedagógicas em sala de aula. De maneira secundária, verificar as potencialidades da incorporação dos exercícios de transmidiação 
nos processos educacionais; demonstrar as implicações dessa tática pedagógica no estímulo ao protagonismo dos estudantes em seu processo de aprendizagem; e sinalizar possíveis mudanças de crenças pedagógicas a partir da aproximação docente com a metodologia da transmidiação.

Consideramos que a metodologia da transmidiação em sala de aula se apresenta como uma tática possível para contribuir na integração entre as práticas pedagógicas dos professores à realidade escolar e aos contextos dos estudantes. Desse modo, utilizamos o conceito de tática cunhado por Certeau (1990, p. 100 apud DURAN, 2012, p. 45) no sentido de que ela origina diferentes maneiras de fazer permitindo aos sujeitos escaparem do controle tornando-se parte do processo ao qual estão inseridos.

Para o autor, enquanto as estratégias são capazes de produzir e impor, as táticas permitem utilizar, manipular e alterar algo, permitindo protagonismo ao sujeito. No caso do estudo aqui proposto, a tática está relacionada ao comportamento do professor frente aos usos de tecnologias para fins didáticos e pedagógicos. Portanto, partimos da hipótese de que, a partir da perspectiva das táticas, nós teremos condições de identificar melhor o delineamento das práticas de ensino pautadas no uso dos dispositivos digitais e na apropriação dos conceitos de transmidiação pelos docentes.

\section{2 . CURSO EM METODOLOGIA DA TRANSMIDIAÇÃO}

O curso UFDOPA foi ofertado pela Subsecretaria de Formação Continuada dos Profissionais da Educação (EAPE) aos professores da rede pública de ensino do Distrito Federal como uma ação de formação continuada da Secretaria de Educação, durante o primeiro e o segundo semestre de 2019. O curso foi formatado com base nos conceitos de convergência digital e dos multiletramentos em uma perspectiva da transmidiação direcionada ao campo da educação. A proposta foi de aproximar os docentes dos dispositivos tecnológicos e suas linguagens para que pudessem trabalhar a transposição e criação de conteúdos, elaborar textos e narrativas baseadas nos exercícios de transmidiação, além de buscar ensino menos centrado no professor.

A formação docente teve uma carga horária total prevista de 90 horas, das quais 30 foram presenciais e 60 a distância. Foram dez encontros presenciais com atividades práticas com a finalidade de contribuir para o conhecimento, exploração e apropriação das diferentes linguagens tanto por meio de aplicativos, dispositivos móveis quanto por programas de computador. Já o ambiente on-line foi utilizado para a disponibilização dos materiais apoio, hospedagem dos trabalhos, fórum de discussões e publicação das atividades e avisos no Google Sala de Aula.

Para que os professores pudessem pensar a criação de narrativas em diferentes linguagens, a proposição do curso foi trabalhar com eles a produção de vídeos, histórias em quadrinhos, tirinhas, imagens, jogos, slides dinâmicos, quiz e avatares por meio dos dispositivos Bitmoji, 
Toondoo², Kahoot, Openshot, Boomerang e Google Apresentações. A proposição foi que fossem realizando experimentações com seus estudantes em sala de aula a partir da apropriação das linguagens e dos usos dos dispositivos e que ao final apresentasse uma proposta se utilizando dos exercícios de transmidiação.

\section{ESCOLHAS METODOLÓGICAS}

O presente trabalho foi formulado metodologicamente a partir da pesquisa qualitativa por ela se apresentar como mais adequada ao nosso objeto de estudo, que pretendeu identificar como repercute uma formação docente continuada em metodologia da transmidiação nas práticas dos professores em sala de aula. Vemos a abordagem como apropriada por seguir um estilo de pesquisa indutivo, com foco no significado individual e relevância da interpretação da complexidade de uma situação.

Também nos valemos da perspectiva multirreferencial por ela oportunizar a pluralidade de leituras no ato de pesquisar e estudar os fenômenos educacionais considerando a heterogeneidade própria das relações educativas. Conforme detalha Ribeiro (2015), tal abordagem não desconhece os saberes específicos das áreas de conhecimento, das disciplinas, mas cria um movimento que se situa para além da afirmação da pluralidade que lhes são inerentes. "As ciências humanas necessitam de explicações e olhares, de perspectivas plurais para dar conta da complexidade dos objetos" (ARDOINO, 1998, p. 4).

A partir dessa referência, utilizamos no desenvolvimento da pesquisa a revisão bibliográfica e documental, a observação não participante, a revisão sistemática de literatura, os registros em diário de bordo, as entrevistas semiestruturadas e análise dos portfolios produzidos pelos estudantes. Esta pesquisa foi submetida e aprovada pelo Comitê de Ética em Pesquisa, por meio da Plataforma Brasil. Foram utilizados os procedimentos e instrumentos requeridos, em respeito às normas de ética em pesquisa com seres humanos, como a assinatura do Termo de Consentimento Livre e Esclarecido.

\subsection{Revisão Bibliográfica}

No intuito de proporcionar maior familiaridade com o problema, de forma a torná-lo mais explícito e auxiliar na construção de hipóteses realizamos a revisão bibliográfica em livros, artigos, teses, dissertações, documentos e normativos. A análise exploratória nos permitiu a

\footnotetext{
${ }^{2}$ O dispositivo Toondoo ficou inativo a partir de 11 de novembro de 2019 em decorrência de uma violência ao site, segundo informação constante no endereço http://www.toondoo.com/. Acessado em 09 de mar. de 2020.
} 
construção de um conhecimento teórico sobre os instrumentos que orientaram a produção e análise dados nos auxiliando na compreensão do problema e na construção dos resultados. Segundo Gil (2002, p. 44) "a pesquisa bibliográfica é desenvolvida com base em material já elaborado, constituído principalmente de livros e artigos científicos".

Procuramos entender melhor a educação na cibercultura, contexto no qual as narrativas transmídia se desenvolveram e de onde se originaram os exercícios de transmidiação e trazer conceitos para nos subsidiar nas análises. Portanto, dessa busca trouxemos a compreensão de que desse contexto de conectividade surgem novas maneiras de aprender e de ensinar, principalmente porque a aprendizagem e a construção do conhecimento estão pautadas na diversidade de opiniões e na realização de múltiplas tarefas como ler, assistir, falar, interagir.

Nesse sentido, a capacidade de criação e de compartilhamento de ideias é favorecida e faz com que o aprendizado seja contínuo e se proporcione a formação de comunidades de aprendizagem. Para Kenski (2012), essa conjuntura exige uma nova forma de ensinar sendo necessário ampliar espaços e outras aprendizagens não escolares, oferecer espaços, tempos, lugares diferenciados e ensino ao estudante e envolver a todos na construção individual e coletiva dos conhecimentos.

Moran (2007) corrobora essa ideia dizendo que é preciso o educador mobilizar e assumir que "seu papel agora é o de gerenciador do processo de aprendizagem, o coordenador de todo o andamento, do ritmo adequado, o gestor das diferenças e das convergências". O autor diz ainda que nesse contexto "o presencial se virtualiza e a distância se presencializa. Os encontros em um mesmo espaço físico se combinam com encontros virtuais, à distância, por meio da internet" (MORAN, 2007, p. 89).

Segundo Valente (2001), o grande desafio para a implantação desta mudança pedagógica é a formação de recursos humanos capazes de passar de uma pedagogia tradicional, diretiva e reprodutora, para uma pedagogia ativa, criativa, dinâmica, libertadora, apoiada na descoberta, na investigação e no diálogo. Para que isso seja possível, o autor diz que é preciso ir além das práticas instrumentais e técnicas.

Dentro perspectiva revisitamos as políticas públicas brasileiras voltadas a formação docente para o uso didático das tecnologias, de 1983 em diante, e contatamos que os programas e projetos não tiveram o resultado esperado. As razões para isso são o descompasso entre os programas e a necessidade real das instituições escolares; o foco na instrumentalização e não na formação continuada; e em capacitações voltadas para a operacionalização de equipamento e não para o uso mais amplo. Tais iniciativas foram se enfraquecendo com o tempo e perdendo sua efetividade, mas não há registros oficiais de que tenham sido de fato encerrados.

\subsection{Estado Da Arte}


Com a sinalização de que há uma demanda crescente por formação continuada docente, principalmente, a que privilegie a realidade dos estudantes e o uso das tecnologias digitais para fins pedagógicos averiguamos também como as pesquisas científicas têm bordado o tema. Nos baseando nas orientações de Medina e Pailaquelén (2010), realizamos uma Revisão Sistemática de Literatura (RSL) que, segundo os autores, "sintetizam os resultados de múltiplas pesquisas primárias, usando estratégias para reduzir viés e erros de azar".

Desse modo, recorremos aos artigos, às dissertações e às teses disponibilizadas na Biblioteca Digital de Teses e Dissertações (BDTD), o Banco de Teses e Dissertações da Capes e o Portal de Periódicos da Capes. Para essa busca, definimos como critérios: 1) a delimitação do período temporal de 2014 a 2018; 2) a escolha de publicações nacionais e 3) a definição de Educação como área de concentração. Além disso, elegemos para esta busca inicial os seguintes descritores: transmídia; formação docente; multiletramentos e multirreferencialidade, que aparecem nos trabalhos de forma cruzada, isto é, são destacados em mais de um trabalho ao mesmo tempo.

Medina e Pailaquilén (2010), alinhados a este pensamento, enfatizam que os pesquisadores precisam da RSL para resumir os dados existentes, refinar hipóteses, estimar tamanhos de amostra e ajudar a definir agendas de trabalho futuro considerados como seus sujeitos. Gomes e Caminha (2014) corroboram essa ideia e afiram que a revisão de literatura é sempre recomendada para o levantamento da produção científica disponível e para a (re)construção de redes de pensamentos e conceitos, que articulam saberes de diversas fontes na tentativa de trilhar caminhos na direção daquilo que se deseja conhecer.

Em uma primeira busca foram encontrados 2.437 trabalhos e com objetivo de possibilitar uma análise mais objetiva dos resultados combinamos palavras chaves. Portanto, concentramos nossa fonte de pesquisa em quatro categorias temáticas: Transmídia e Educação; Formação Docente e Tecnologia; Multiletramentos e Tecnologia e Multirreferencialidade e Educação. Dessa combinação obtivemos 181 publicações, que foram submetidas a leitura dos títulos observando qual delas tinham uma relação direta com a temática proposta descartando assim aquelas que não faziam tal associação. Nos casos em que apenas a leitura do título não permitiu a filtragem, os resumos foram analisados para averiguar a apresentação do tema de pesquisa, os objetivos, a metodologia e os resultados até a seleção das dez produções: quatro dissertações, três teses e três artigos.

Portanto, ficou evidenciado que a produção científica acerca da aplicação da metodologia da transmidiação em contextos educacionais é pouco expressiva. A maior concentração dos estudos relacionados a este campo ainda está restrita à leitura, ao desenvolvimento da escrita e ao letramento digital, baseado no contexto das narrativas transmídia. Com isso, a formação docente voltada ao uso pedagógico de tal metodologia se mostra um caminho promissor para a realização 
de novas pesquisas se valendo também da confirmação da potencialidade da transmidiação para o campo educacional por meio dos estudos já realizados.

\subsection{Observação Não Participante}

Para a escolha dos sujeitos de pesquisa o caminho foi uma observação estruturada não participante do curso UFDOPA. Tratou-se de uma aproximação com o campo de estudo no papel expectador sem gerar interferências e extrair subsídios necessários para investigação. Isso se deu em dois momentos, o primeiro deles foi acompanhar o curso piloto, realizado entre abril e junho de 2019, e a fase seguinte foi a observação de uma segunda oferta reformulada do curso entre agosto e outubro de 2019. Nesta última fase, escolhemos quatro docentes para serem entrevistados, dois para serem acompanhados na aplicação dos exercícios de transmidiação em sala de aula e uma turma para ter os portfólios dos estudantes analisados.

De acordo com Lakatos e Marconi (2003), a observação ajuda o pesquisador a identificar e a obter provas a respeito de objetivos sobre os quais os indivíduos não têm consciência, mas que orientam seu comportamento. Nesse sentido, elas defendem que esse procedimento desempenha papel importante nos processos observacionais, no contexto da descoberta, e obriga o investigador a um contato mais direto com a realidade sendo, portanto, o ponto de partida da investigação social.

Observar o curso piloto foi fundamental para o desenrolar da pesquisa por ter trazido elementos que colaboraram para uma melhor compreensão de questões relacionadas à formação docente, a sua relação com as tecnologias e as convicções pedagógicas dos professores. Além disso, permitiu a escolha do CRTE de Taguatinga como lócus de pesquisa, na segunda oferta do curso, considerando o fato de ele ter sido o local com maior número de cursistas, contemplado docentes de várias regiões administrativas do DF e apresentado professores de todos os níveis de ensino.

Além da formação docente, a aplicação dos exercícios de transmidiação com os estudantes em duas turmas foram observados. Por meio de uma escrita livre anotamos em Diário de Bordo o maior número de informações acerca dos fenômenos que se apresentaram como, por exemplo, os detalhes das atividades envolvendo a formação dos docentes, sua rotina durante as atividades, os relatos de suas experiências pessoais ou decorrentes das atividades de formação, os acontecimentos cotidianos, a arquitetura escolar a qual estavam inseridos e as atividades culturais que foram desenvolvidas durante o período de formação. Tais ponderações foram necessárias durante os registros das experimentações nas escolas, as reações dos alunos, suas dificuldades, seu entrosamento e participação no trabalho.

A observação também foi o meio pelo qual foi possível estabelecer critérios de seleção dos sujeitos da pesquisa. Estabelecemos como critérios para escolha: 1) o professor estar em 
regência; 2) apresentar uma proposição de atividade que mais se aproximasse da ideia de transmidiação e 3) sinalizar o interesse em realizar as experimentações em sala de aula. Além disso, definimos que seriam escolhidos professores de cada etapa da Educação Básica.

Portanto, fizemos a seleção de quatro professores entre os 14 participantes do curso, uma da Educação Precoce, uma do Ensino Fundamental I, uma do Ensino Fundamental II e um do Ensino Médio. Desses, dois foram acompanhados em suas experimentações em sala de aula levando-se em conta o alinhamento de suas propostas a metodologia da transmidiação e o uso do maior número de dispositivos em suas atividades. Dessas observações, selecionamos uma turma com 27 alunos em razão do volume de trabalho produzido e o uso de vários dispositivos.

\subsection{Entrevistas Semiestruturadas}

Para a produção dos dados qualitativos também optamos por utilizar como instrumento a entrevista semiestruturada. De acordo com Manzini (2016), esta é indicada para estudar um fenômeno com uma população específica a exemplo um grupo de professores e/ou um grupo de alunos a partir de um roteiro com perguntas abertas. Para o autor, tal entrevista confere confiança ao pesquisador e possibilita a comparação das informações entre os participantes. Nessa perspectiva, aspecto comparativo foi utilizado visando perceber as nuances do processo formativo dos professores que reverberaram em suas práticas na sala de aula.

Nesse sentido, foram definidos como eixos centrais para a entrevista: 1) a prática de transmidiação por meio das experimentações; 2) a expansão de narrativas; 3) o uso das multilinguagens; 4) a apropriação docente da metodologia; 5) a viabilidade pedagógica do uso dos dispositivos acerca da formação continuada. De forma complementar, pretendíamos verificar a relação dos professores com as TDICS, a relevância das tecnologias educacionais para um ensino alinhado à realidade dos estudantes e os desafios para incorporar mudanças ao método tradicional de ensinar.

As entrevistas ocorreram de forma individual, em dias e horários distintos, de comum acordo com cada professor no ambiente escolar em que trabalham, com o estabelecimento de um limite de 30 minutos para sua realização e por questões abertas previamente formuladas. Embora houvesse os questionamentos comuns a todos os professores, outros surgiram a partir das respostas eram dadas sendo em alguns até feitos contrapontos pelo entrevistador.

Para as análises, incialmente foi feita a transcrição das entrevistas e a posterior inserção no software Iramuteq. Utilizamos a nuvem de palavras, que nos apresentou graficamente os termos como maior predominância sendo que os mais presentes ficaram dispostos ao centro da imagem. Também nos valemos da análise de similitude, que segundo Camargo e Justo (2013), mostra um grafo que representa a ligação entre as palavras do corpus textual. Esse recurso objetiva 
identificar os núcleos de significação, a partir da agrupação dos termos relevantes, chamados de eixos ou troncos.

\begin{abstract}
A partir da análise textual é possível descrever um material produzido por um produtor, seja individual ou coletivamente, como também pode-se utilizar a análise textual com a finalidade relacional, comparando produções diferentes em função de variáveis específicas que descrevem quem produziu o texto (CAMARGO, JUSTO, 2013, p. 2).
\end{abstract}

Foram observadas as frequências e a conexidade entre palavras bem como o agrupamento dos termos de acordo com sua frequência. Por meio dessas frequências foi possível estabelecer categorias de análise que perpassam o discurso dos vários sujeitos ouvidos. Para a seleção das categorias nos valemos da triangulação entre os aspectos teóricos, as análises de dados e as observações de campo.

\title{
3.5 Produção Dos Alunos
}

Dentre os professores escolhidos para serem acompanhados em suas experimentações escolhemos uma turma do $5^{\circ}$ ano do Ensino Fundamental I para ter os portfólios produzidos pelos estudantes analisados. Essa escolha surgiu da observação não participante em sala de aula considerando a pluralidade de atividades realizadas, o uso de mais de mais dispositivo e o alinhamento com a metodologia da transmidiação.

Eles trabalharam com a produção histórias em quadrinhos, com e sem orientação da professora; elaboraram videoaulas com utilização de avatares, sons, imagens e texto; fizeram atividades gamificadas com o uso do kahoot e, em todas as etapas, produziam depoimentos escritos sobre a experiência com o uso dos dispositivos.

Essas produções passaram por uma análise temática utilizando como referência os conceitos de transmidiação, observando as potencialidades e as fragilidades apresentadas no processo de execução bem como o resultado final dessa intervenção. Nessa observou-se o envolvimento dos estudantes, o desempenho nas atividades, o uso das diferentes linguagens, o desenvolvimento da escrita e da leitura, a identificação com o letramento digital, a criatividade e o desenvolvimento de habilidades.

A análise de conteúdo temática foi adotada, pois segundo Bardin (1979, apud Gomes, 2007 , p. 86) esta define o tema como conceito central, como: "unidade de significação que se liberta naturalmente de um texto analisado segundo critérios relativos à teoria que serve de guia à leitura". Portanto, seguindo os passos de Gomes (2007), utilizamos inferências a partir da descrição dos conteúdos explícitos para se chegar a dimensões interpretativas do campo semântico que vão além da mensagem.

Segundo o autor, a noção de tema compõe um feixe de relações que pode ser representado por uma palavra ou uma frase e, portanto, a análise temática consiste em descobrir os núcleos de 
sentido que compõem uma comunicação. Desse modo, extraímos indicadores e constatações que ao serem colocados em diálogo com as entrevistas, as observações de campo e as bases teóricas deste estudo, possibilitaram a construção de categorias de análise.

\section{4 . ESCOLHAS METODOLÓGICAS}

Para as análises, as entrevistas foram degravadas e submetidas ao Iramuteq que realizou uma análise lexicográfica. Observamos as frequências utilizando as formas ativas, ou seja, os verbos, os advérbios, os adjetivos e os substantivos, por darem melhor sentido as frases. Entretanto, para evitar frequências excessivas optamos por excluir os advérbios mantendo os demais. A primeira busca foi pela frequência de palavras das narrativas. Desse modo, o corpus textual das entrevistas com os docentes nos forneceu uma média de 1.225 palavras mais frequentes.

A palavra com maior recorrência é aluno $(36)^{3}$ nos indicando, portanto, uma centralidade do discurso dos docentes na figura do estudante. Na sequência, aparece o termo utilizar (32) cujo sentido é "fazer emprego de" e que dialogam com outros termos mais citados com mesmo significado como usar (21) e uso (18). Posteriormente, estão as expressões professor (30) e aula (27), que representam o contexto da educação formal e foram mais citados que escola (20) e sala (16) indicando aí um descolamento do processo de aprendizagem do espaço físico das instituições de ensino.

O ranqueamento permitiu perceber que os termos estar (23) e gente (21) trazem uma ideia de pertencimento e humanização se pensarmos, por exemplo, em uma participação maior dos estudantes nos processos de ensino, conforme indicamos nos processos de transmidiação. Em uma outra perspectiva, observamos que ferramenta (17), internet (17) e tecnologia (17) são termos presentes no discurso dos professores e que dialogam com o conceito de uso dentro dos processos de ensino.

Em sua fala, a professora Ametista ${ }^{4}$ exemplificou como isso funciona.

Eu fiz uma experiência simples que foi colocar imagens do livro didático no Google Apresentações trabalhando o mesmo conteúdo sem folhear o livro e o resultado foi outro. Você consegue atrair a turma mais para perto de você. Alguns alunos têm dificuldade de escrever e só de visualizar eles já conseguem aprender (AMETISTA, 2019).

De forma parecida, a professora Jade (2019) disse pensar que hoje não há como retardar a inserção das tecnologias nos processos de educação formal. "Têm que acontecer principalmente

\footnotetext{
${ }^{3}$ Utilizamos os numerais entre parênteses para indicar quantas vezes aquela palavra apareceu no corpus de texto analisado no software Iramuteq.

${ }^{4}$ Neste estudo, utilizamos a nomenclatura de pedras para nos referirmos aos professores entrevistas de forma a manter o anonimato de ambos.
} 
porque às crianças de hoje em dia nascem nesse contexto. Se a escola não leva isso a sério a aprendizagem se torna desinteressante", (JADE, 2019)

Para entender as relações de sentido no corpus textual utilizamos a análise de similitude o Iramuteq nos permite compreender as conexões estabelecidas entre as palavras a partir de grafos, ou seja, estruturas combinatórias utilizadas para representar relações entre elementos de uma estrutura de texto. Estes elementos são representados por pontos denominados vértices e as relações são mostradas por segmentos unindo dois destes pontos, denominados arestas. Portanto, assim ficaram demonstradas visualmente as relações das palavras entre si, as tendências, características e ausências de itens lexicais no material analisado.

Figura 1 - Análise de similitude das entrevistas com os professores

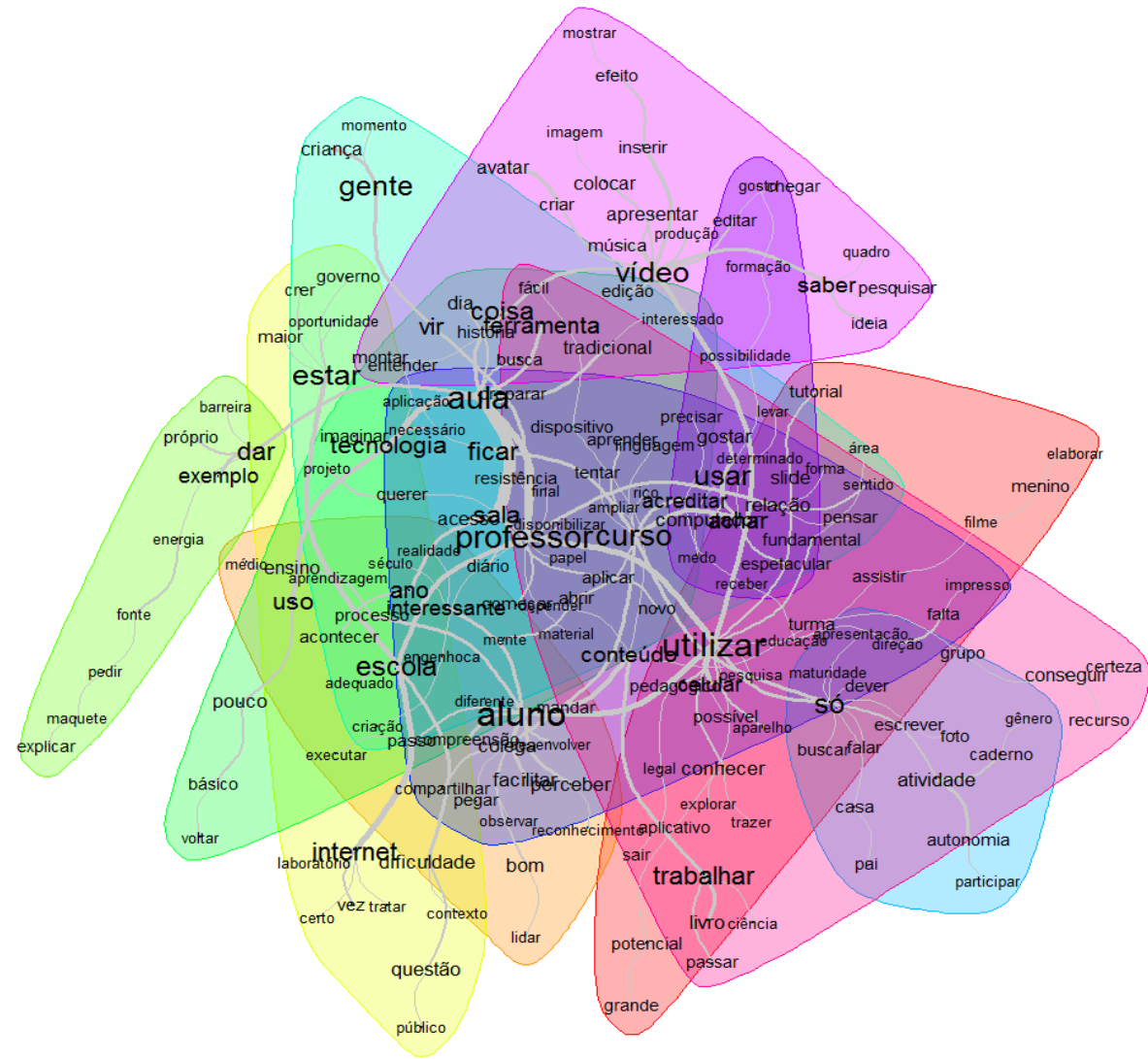

Fonte: Extraído do Iramuteq (2020).

A disposição gráfica e as conexões entre as palavras nos indicam um discurso comum entre os entrevistados a partir do destaque dado aos termos aluno (33), utilizar (32), professor (30), vídeo (27), aula (27) e curso (26), que mais registraram interligações a outros e ocuparam a parte central da figura. Portanto, podemos pensar, por exemplo, em uma crença de que "o estudante e/ou o professor usar tecnologia em sala de aula é uma repercussão do curso", segundo as falas dos professores. Além disso, sinalizaram um foco maior dos estudantes neste processo confirmado no gráfico a partir da descentralização dos termos escola (20) e sala (16).

A professora Cristal (2019), por exemplo, percebeu e relatou que a partir da realização das experimentações em sala de aula utilizando os dispositivos tecnológicos os alunos 
apresentaram mais autonomia durante a execução das atividades demonstrando um envolvimento maior.

Percebi mais autonomia durante o processo, principalmente naqueles alunos com transtornos como dislexia e autismo. Eles foram inseridos no grupo, puderam trabalhar com outros meninos. Eles se enxergaram capazes chegando até mim e dizendo que conseguiram fazer o trabalho, editar o vídeo, inserir efeitos. E foi surpreendendo, pois houve produções bem elaboradas e criativas (CRISTAL, 2019).

Nos esquemas gráficos e as falas dos docentes também destacaram a questão da infraestrutura tecnológica nas escolas como um elemento dificultador para a adoção de atividades pedagógicas nessa linha. Penso que a maior dificuldade que encontramos é a questão de políticas públicas em relação ao aparelhamento das escolas para atender essa demanda (BERILO, 2019).

Outro destaque foi o interesse de outros professores que não fizeram o curso em adotar a metodologia nas escolas onde as experimentações ocorreram. Algumas colegas me viram aplicando as atividades e se interessaram. Já temos um grupo de professoras interessadas em no ano que vem começar utilizando os avatares no Bitmoji (JADE, 2019).

Frente a estas evidências no discurso dos docentes surgiram alguns núcleos temáticos que foram a base para as categorias de análise como, por exemplo, a modificação das práticas de ensino a partir de formação continuada para o uso de tecnologias; o destaque maior para o aluno dentro desse contexto de aprendizagem; a precariedade da infraestrutura tecnológica nas escolas; o tradicionalismo do ensino desconectado de práticas diferenciadas; e os espaços geográficos deste processo mais descentralizados da escola e da sala de aula.

\subsection{Perspectivas dos estudantes}

Nas experimentações os estudantes do $8^{\circ}$ ano expandiram as narrativas do filme " $O$ Menino que Descobriu o Vento ${ }^{5}$ ", exibido em sala de aula, e que conta a história de um garoto que construiu uma engenhoca com um sistema de moinho e de bombeamento de água que transformou a vida dos moradores de sua aldeia. Inspirados na ficção os estudantes também tiveram que criar uma engenhoca e apresentar sua construção e os conceitos nela empregados em um vídeo feito por meio do Openshot ou outro em dispositivo que considerassem mais adequado.

No processo de criação tiveram que elaborar um roteiro com uma história e as respectivas narrativas, inserir seus avatares feitos no Bitmoji, utilizar efeitos, inserir sons e imagens. No trabalho, que envolveu a participação de professores Ciências, Língua Portuguesa e Artes, os estudantes demonstraram empolgação, foram criativos, utilizaram de várias linguagens, trabalharam em cooperativante e desenvolveram a atividade com autonomia.

\footnotetext{
${ }^{5}$ O Menino que Descobriu o Vento narra a saga de Kamkwamba para acabar com a fome na sua vila, provocada pela seca. A produção está disponível em: <https://www.netflix.com/br/>. Acessado em 05 de mai. 2020
} 
Na turma de $5^{\circ}$ ano, a professora trabalhou com os alunos inicialmente a produção de histórias em quadrinhos utilizando o Kahoot e/ou outro dispositivo que os alunos considerassem mais oportuno. Posteriormente, explorou a produção de vídeos utilizando o Openshot e/ou outro dispositivo que os alunos sentissem mais facilidade. A ideia era produzir um vídeo explicado sobre fontes de energia a partir da construção de uma maquete no qual teriam que explorar recursos sonoros, efeitos, texto e inserir avatares feitos no Bitmoji. A proposta era para se apresentarem como youtubers.

Dado o maior número de experimentações e de dispositivos utilizados escolhemos a turma do $5^{\circ}$ ano para analisar os portfólios. Parte das atividades era produzir um parágrafo de texto descrevendo o que acharam de cada experiência e do trabalho com os dispositivos. Esses textos foram inseridos no iramuteq para entender a perspectiva dos estudantes.

Figura 2 - Nuvem de palavras acerca do uso dos dispositivos

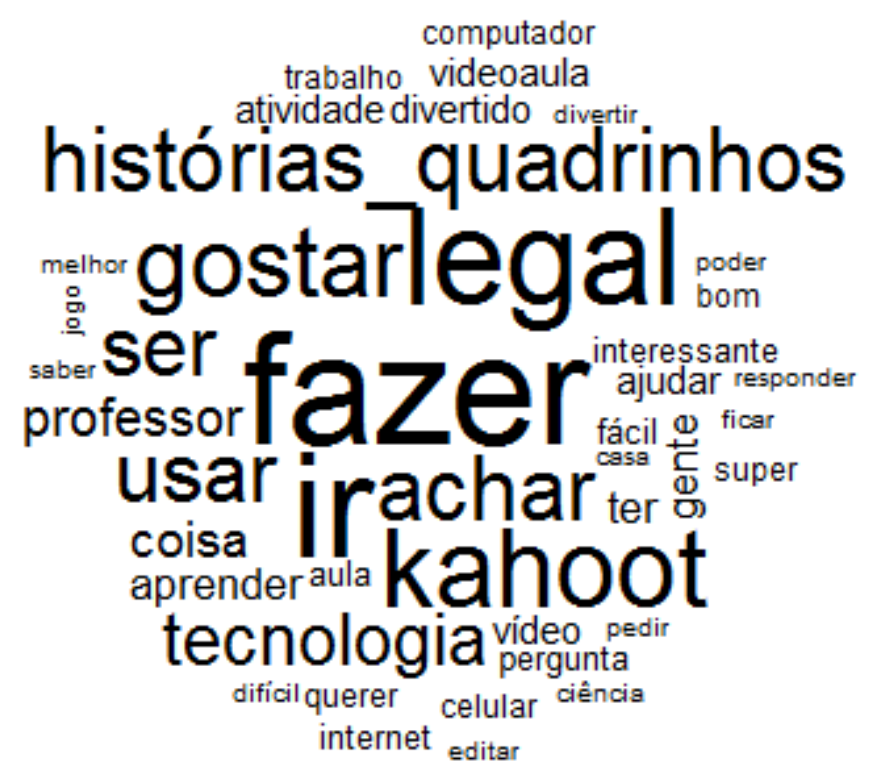

Fonte: Extraído do Iramuteq (2020)

Do corpus de texto analisado a palavra fazer (38) é a que mais se destaca rodeada das expressões: ir (35), legal (32), kahoot (25), gostar (22), achar (20), histórias em quadrinhos (20), ser (18) e usar (18). Dessa composição gráfica podemos inferir que os estudantes se identificaram com o uso dos aplicativos e do trabalho com as narrativas. Nesse contexto, sinalizaram a preferência pelo kahoot, seguido da produção de HQs e por último as produções de videoaulas. Entendemos que nesse contexto mostrado na figura o fazer sugere uma ideia de realizar determinada tarefa e associado ao verbo ir dá uma noção de proatividade.

Por outro lado, na região periférica do gráfico aparece professor (10) indicando estar deslocado do discurso central dos estudantes. Outros termos como aula (05), trabalho (04), difícil (03) e pedir (03) também aparecem com menor frequência e nos apresentam indicativos de que as atividades foram desafiadoras em menor intensidade, atuaram mais autônomos e o contexto de sala não teve significância. 
Em uma outra perspectiva, as informações nos levaram a uma interpretação de que o uso do dispositivo em uma dinâmica de sala de aula repercutiu positivamente tendo em vista a dinâmica de games, apesar da dificuldade de alguns. Além disso, nos levou a concluir que os estudantes tiveram apropriação das linguagens. Essa confirmação alinha-se com as atuações desses jovens fora da escola ao produzirem conteúdos para redes sociais, interagirem e consumirem informação por meio internet.

\subsection{Portfólios dos estudantes}

Nas produções iniciais das histórias em quadrinhos, os estudantes se utilizaram de humor e deram tom de brincadeira nos textos, onomatopeias e nas figuras utilizadas para falar sobre frações, derivação, sistemas digestivo e respiratório, revisão de classes gramaticais, multiplicação, ida ao cinema e aulas de bale, temáticas escolhidas livremente por eles. Em uma segunda experiência, ampliaram seu repertório e aprimoraram suas produções, utilizando mais elementos gráficos, as falas foram mais próximas das expressões dos personagens e as falas foram mais bem exploradas.

Foi possível identificar nas produções sinais de proatividade, interesse, criatividade na construção dos diálogos e superação de desafios, considerando que o dispositivo Make Beliefs Comix, utilizado em substituição ao Toondoo que apresentou instabilidade à época, estava em inglês e isso não foi impeditivo para realizarem a atividade. Essas mesmas características foram notadas na produção das videoaulas quando demonstraram habilidades para lidar com os dispositivos, as linguagens exploradas, a elaboração do roteiro e a apresentação dos conteúdos explorados.

Quanto ao uso do Kahoot em sala de aula foi possível identificar empolgação nos estudantes, trabalho de equipe, interesse na atividade e a professora mediando a dinâmica. Segundo o estudante Jerivá (2019) "usar o kahoot foi muito legal, mais que as histórias em quadrinhos, porque ele é legal e não é demorado". A mesma preferência manifestou a estudante Pereira (2019) ao compartilhar que para ela "o kahoot teve um papel importante por ter ajudado na revisão para a prova de Ciências, que fez com que pudesse gabaritar a prova".

A partir da apropriação das linguagens a professora Cristal, da turma de $5^{\circ}$ ano, e seus alunos fizeram recontos do livro "De Bruxa Tenebrosa à Fada Graciosa". Depois de lerem o livro, produziram releituras da história contada por meio de peça teatral, elaboração de um livro com as fotos da apresentação teatral e textos escritos pelos estudantes, além da elaboração de vídeo com as imagens e as gravações feitas. Isso demonstrou que os conceitos de transmidiação foram incorporados e utilizados nas práticas de ensino em sala de aula.

\subsection{Categorias temáticas}


A partir dos dados empíricos e das análises realizadas foram criadas categorias de codificação temáticas das significações das palavras e expressões oriundas das falas dos professores e dos alunos, dos sentidos indicados pelas nuvens de palavras e pelos gráficos de similitudes bem como das observações de campo. São elas: protagonismo e colaboração; convergência e instantaneidade; infraestrutura e usos de táticas pelos docentes; interdisciplinaridade e multiplicação; e tradicional x transmidiado.

A autonomia, a proatividade e o trabalho cooperativo envolvendo colegas, familiares e professores foram aspectos evidenciados nos processos de experimentação em sala de aula. Essas características emergiram nos destacando assim os conceitos de protagonismo e de colaboração. Essa perspectiva faz parte da metodologia da transmidiação que identifica no trabalho pedagógico conjunto e autônomo uma alternativa para aliar o ensino tradicional ao inovador.

Ficou evidenciado que por meio de um processo moldado nas experiências os estudantes se tornaram mais autônomo e estimulados em suas decisões. Outra característica assinalada foi o trabalho pautado na Educação Colaborativa ao trabalharem em grupos, remotamente, com auxílio dos pais e a mediação da professora. Os estudantes comprovaram também que a internet e os meios digitais lhes foram instrumentos eficazes para a realização dos trabalhos ao recorreram aos sítios de pesquisa, procuraram tutoriais, buscar técnicas de produção de vídeo e outros subsídios para auxiliar na execução das tarefas.

Nas experimentações, os estudantes também demonstraram que estão conectados ao mundo em tempo real por meio das tecnologias, com as informações na palma da mão de forma acessível e que a utilização destas alternativas nas práticas de ensino fez diferença. O celular conectado à internet foi o principal recurso utilizado por eles para pesquisar, baixar os aplicativos, comunicar entre si, receber as instruções da professora e realizar os trabalhos. Frente a isso, entendemos que essa convergência e rapidez se apresentaram como uma das categorias pela proximidade de ambas.

Uma das particularidades da convergência digital é a celeridade no acesso às informações e à obtenção de resultados em menor tempo evidenciada na preferência para a utilização do Kahoot e não tanto pela produção de vídeo no Openshot ou no dispositivo que escolheram. Essa predileção se justifica pelas características do Kahoot, que se baseia na gamificação, com sistema de feedback, resultados instantâneos, competição e cooperação. A produção das videoaulas demandou mais tempo, pesquisa, construção das maquetes, a gravação e a edição sendo vistas pelos estudantes como desafio a mais, porém consideraram a atividade muito próxima daquilo que já produzem e divulgam nas redes sociais e aplicativos de mensagens utilizando o celular.

Concluímos ainda que o atual contexto de comunicações rápidas, adesão maciça dos jovens em idade escolar, celeridade na produção de conhecimentos e acesso facilitado pelo avanço 
das tecnologias, evidenciado por esta pesquisa, precisa ser considerado pelas instituições de ensino, com a utilização, como no estudo em questão, da tática de formação docente continuada.

A precariedade da infraestrutura nas escolas públicas no que diz respeito aos aparatos tecnológicos foi predominante nos discursos analisados. A ausência de laboratórios de informática, computadores sem funcionamento e indisponibilidade de internet foram recorrentes nas falas tanto dos professores quanto alunos. Frente a este cenário os docentes disseram adotar como saída o uso do computador pessoal na sala de aula, o compartilhamento da internet do seu aparelho de celular com os alunos e principalmente o direcionamento das atividades para serem feitas em casa. Portanto, vimos uma relação direta entre infraestrutura e táticas docentes.

Dos quatro professores entrevistados, metade afirmou que os laboratórios de suas escolas estavam sem condições de uso ou subutilizados. A obsolescência dos equipamentos também foi apontada pelos professores como um dos desafios para a conectividade nas escolas gerando com isso um desestímulo à implementação de ações que busquem a incorporação de novas práticas de ensino por parte dos professores. Diante dessa realidade, uma alternativa é buscar implementação de ações que partam da prática docente como o uso do computador pessoal e internet móvel para aplicação de atividades e o planejamento de atividades em que os estudantes possam utilizar os aparatos tecnológicos de suas casas.

A viabilidade de aplicar os exercícios de transmidiação em várias disciplinas também foi mais uma conclusão da análise das experimentações em sala de aula e da observação do curso de formação docente. Portanto, temos a interdisciplinaridade como uma categoria junto com multiplicação, uma vez que além de aplicar em vários contextos os professores cursistas atuaram como disseminadores das ideias e princípios da transmidiação em suas unidades escolares.

Das produções vieram demonstrações de que as narrativas com os dispositivos podem ser aplicadas a vários tipos de conteúdo a exemplo das histórias com a temática de Matemática, História, Língua Portuguesa e Ciências. A produção dos vídeos também permitiu trabalhar com várias linguagens e temáticas, incluindo as do livro didático. A interdisciplinaridade gerou um estímulo a outros professores a aderirem tal proposta a partir da apropriação que os docentes tiveram com as linguagens a partir das experimentações.

A incorporação da metodologia da transmidiação às práticas de ensino escolar, segundo as experimentações aqui analisadas, trouxe ao modelo tradicional de ensinar centrado na figura do professor uma mudança a partir da integração de dispositivos e ferramentas tecnológicas no processo de ensino e aprendizagem. Diante das evidências aqui encontradas entendemos que essa relação tradicional $\mathrm{x}$ transmidiado também é outra categoria.

A partir das falas, dos trabalhos e das experimentações evidenciamos que a incorporação de novos elementos, como no caso da utilização dos dispositivos tecnológicos, aproximou o processo de ensino e aprendizagem da realidade dos alunos, envolvendo-os, estimulando-os à 
colaboração e ao protagonismo. Corroboramos também que o tradicional e o novo precisam andar juntos, no intuito de potencializar a formação dos estudantes de forma atrativa e engajada.

\section{5 . CONSIDERAÇÕES FINAIS}

A partir das análises concluímos que os estudantes participantes da pesquisa se mostraram, durante as experimentações, mais autônomos, criativos, colaborativos, com protagonismo, identificados e engajados com o que estavam fazendo, demonstrando entusiasmo, e mais adeptos à gamificação para fins didáticos, com preferência pelas dinâmicas de resultados mais imediatos. Para se chegar a estas afirmações fizemos a análise temática das histórias em quadrinhos produzidas por eles em dois momentos, sem orientação da professora e depois de orientados; das videoaulas, das dinâmicas com o Kahoot em sala de aula e dos depoimentos escritos pelos estudantes e entregues à professora respondendo como foi realizar os trabalhos com os dispositivos.

As narrativas das entrevistas depois de submetidas a análise do software Iramuteq e cruzadas com as observações realizadas em diário de bordo nos levaram a constatar que: a aproximação com os dispositivos colaborou para a implementação de atividades diferenciadas em sala de aula; o papel do professor no processo se modificou para uma figura de mediador e não apenas de expositor de conteúdo; o registro do envolvimento de outros docentes nas experimentações realizadas pelos cursistas em suas escolas; a precariedade na infraestrutura tecnológica é um dos empecilhos para execução das experimentações; a possibilidade de trabalhar com alunos portadores de necessidades especiais e com crianças da educação precoce com adaptação de conteúdo; e o entendimento de que a metodologia da transmidiação é uma alternativa para realização de novas práticas de ensino podendo ser aplicada a todos os níveis de ensino.

A partir do cruzamento entre os diferentes dados qualitativos concluímos que aproximar os docentes das linguagens dos dispositivos tecnológicos por meio de uma formação continuada em metodologia da transmidiação é uma tática capaz de trazer o universo do estudante para as práticas de ensino fazendo-o participar do processo e que o método tradicional de dar aulas seja desenvolvido de nova maneira. Além disso, é uma forma de compensar a falta de formação acadêmica direcionada para o uso das TDICs em sala de aula e estreitar a relação dos docentes com as tecnologias e suas linguagens tendo em vista que nasceram em gerações diferentes dos estudantes, que as dominam muitas vezes com mais propriedade.

Ao finalizar este trabalho, nos vem a certeza de que o curso é uma brecha para minimizar a carência de formação continuada para os professores das escolas públicas nessa área e, mais que isso, uma ruptura ao pensamento homogeneizador dentro do espaço educacional. Também foi evidenciado que a transmidiação é um caminho possível para a construção de um processo 
formativo alinhado às demandas dos estudantes e de uma educação libertadora que, segundo Freire (1996), necessita que o educando crie suas representações do mundo, pense as estratégias para solução de seus problemas, aprenda e se compreenda como sujeito da história.

Temos a certeza de que ainda há muito caminho a ser percorrido dentro do contexto da transmidiação enquanto tática pedagógica. Dentre as saídas possíveis estão; o uso da metodologia na educação especial, o trabalho pedagógico com os microcontos publicados nas redes sociais; a inserção deste tipo de abordagem dentro da formação acadêmica nos cursos superiores; a alfabetização visual e escrita na perspectiva dos multiletramentos; a alfabetização multimodal, a transmidiação no campo da educação aberta e o uso pedagógico das fanfics para avaliar gêneros textuais, autoria, colaboração e formas escritas.

Da conclusão de que a transmidiação é algo que aponta para o novo, para a diferenciação e não para a repetição tiramos a motivação para realizar, posteriormente, um estudo longitudinal, a partir das futuras turmas ofertadas do curso junto à EAPE, dentro das ações de formação continuada da Secretaria de Educação do DF. A perspectivamente é ampliar a discussão em outros estudos tendo em vista que o assunto não se esgotou. Portanto, esta é uma obra aberta e em construção, mas que está sendo fechada temporariamente com a itinerância, os resultados e as reflexões abertas. Esperamos que as constatações aqui apresentadas abram portas para novos estudos e que estes venham a contribuir para a aprimoramento dos processos de ensino na educação pública.

\section{REFERÊNCIAS}

ARDOINO, J. Abordagem multirreferencial (plural) das situações educativas e formativas. In: BARBOSA, J. (org.). Multirreferencialidade nas ciências e na educação. São Carlos: EdUFSCar, 1998. p. 24-41.

BAUMAN, Z.; LEONCINI, T. Nascidos em tempos líquidos. São Paulo: Zahar, 2018.

CAMARGO, B.; JUSTO, A. Tutorial para uso do software Iramuteq. Florianópolis: UFSC, 2013. Disponível em: http://www.iramuteq.org/documentation/fichiers/tutoriel-enportugais. Acesso em: 02 abr. 2020.

COMITE GESTOR DA INTERNET NO BRASIL. Pesquisa sobre o uso da internet por crianças e Adolescentes no Brasil, 2017. 2018. Disponível em: <https://cetic.br/pesquisa/ kidsonline/publicacoes>. Acesso em: 18 mai. 2020.

COMITE GESTOR DA INTERNET NO BRASIL. Pesquisa sobre o uso da internet por crianças e Adolescentes no Brasil, 2018. 2019. Disponível em: <https://cetic.br/pesquisa/ kidsonline/publicacoes>. Acesso em: 05 mai. 2020

GIL, A. C. Como elaborar projetos de pesquisa. São Paulo: Atlas, 2002.

GOMES, R. Análise e interpretação de dados de pesquisa qualitativa. In: MINAYO, M. C. S. (org.). Pesquisa social: teoria, método e criatividade. 34. ed. Petrópolis: Editora Vozes, 2015. p. 79-108. 
GOMES, I. S.; CAMINHA, I. O. Guia para estudos de revisão sistemática: uma opção metodológica para as Ciências do Movimento Humano. Movimento: Revista de Educação Física da UFGRS, Porto Alegre, v. 20, n. 1, p. 395-411, jan./mar. 2014. Disponível em: <https://seer.ufrgs.br/Movimento/article/view/41542>. Acesso em: 10 mar. 2020.

JENKINS, H. Cultura da convergência. São Paulo: Aleph, 2009.

KENSKI, V. M. Educação e tecnologias: o novo ritmo da informação. 8. ed. Campinas: Papirus Editora, 2015.

LAKATOS, E. M.; MARCONI, M. A. Fundamentos de Metodologia Científica. 5. ed. São Paulo: Ed. Atlas, 2003. 311 p.

LÉVY, P. Cibercultura. 3 ed. São Paulo, 1999. 270 p. (Coleção Trans).

MANZINI, E. Uso da entrevista em dissertações e teses produzidas em um programa de pósgraduação em Educação. Revista Percurso, v. 4, n. 2, p. 149-171, 2012.

MEDINA, E. U.; PAILAQUILÉN, R. M. B. A revisão sistemática e a sua relação com a prática baseada na evidência em saúde. Revista Latino-Americana de Enfermagem, Ribeirão Preto, v. 18, n. 4, p. 1- 8, jul./ago. 2010. Disponível em: http://www.scielo.br/pdf/rlae/v18n4/pt_23. Acesso em: 30 mar. 2020.

MORAN, J. M. A educação que desejamos: novos desafios e como chegar lá. Campinas: Papirus, 2007.

RIBEIRO, M. R. A sala de aula no contexto da cibercultura: formação docente e discente em atos de currículo. 2015. 207 f. Tese (Doutorado) - Faculdade de Educação, Universidade do Estado do Rio de Janeiro - UERJ, Rio de Janeiro, 2015.

SANTAELLA, L. Comunicação ubíqua: repercussões na cultura e na educação. São Paulo: Paulus, 2013.

SERRES, M. Polegarzinha. Rio de Janeiro: Bertrand Brasil, 2013.

VALENTE, J. A. Formação de Educadores para o uso da informática nas escolas. Porto Alegre: Artmed, 2001.

VERSUTI, A.; SILVA, D. A transmidiação como uma escrita de resistência. Revista Linha Mestra, n. 33, São Paulo, 2017 